\title{
FIBRA MUSCULAR, DESEMPENHO E A QUALIDADE DA CARCAÇA DE QUATRO GRUPOS GENÉTICOS DE SUÍNOS*
}

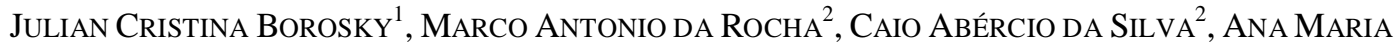 \\ BRIDI $^{2}$, ROBERTA ABRAMI MONTEIRO ${ }^{3}$ \\ 1 - Aluna do Programa de Pós-Graduação em Ciência Animal da Universidade Estadual de Londrina, PR. \\ 2 - Professores Doutores do Departamento de Zootecnia da Universidade Estadual de Londrina, PR - ambridi@uel.br \\ 3 - Aluna do Programa de Pós-Graduação em Ciência Animal da Universidade Estadual de Londrina, PR \\ ( ) Projeto financiado pelo CNPq.
}

O objetivo com este trabalho foi verificar o desempenho e a qualidade da carcaça de quatro linhagens genéticas de suínos e correlacionar esses dados com o número e diâmetro das fibras musculares. Foram utilizados 48 suínos, distribuídos em um delineamento completamente casualizados em esquema fatorial 4 × 2 (4 linhagens e 2 gêneros). As linhagens genéticas avaliadas foram: linhagem comercial para carne; linhagem comercial para prolificidade; cruzados Landrace x Large White; e sem genética definida. Foram avaliados o ganho de peso, o consumo de ração, a conversão alimentar, as carcaças e o número e diâmetro das fibras musculares do longissimus dorsi. As linhagens selecionadas para deposição de carne apresentaram maior número de fibras e o grupo sem genética definida o menor $(\mathrm{P}<0,05)$. Os animais Landrace $\mathrm{x}$ Large White apresentaram maior diâmetro celular $(\mathrm{P}<0,05)$. Linhagens selecionadas para deposição de carne apresentaram melhor desempenho e qualidade de carcaça que os animais sem genética definida $(\mathrm{P}<0,05)$. Os machos castrados apresentaram menor número de fibras, pior conversão alimentar e características de carcaça. Através da análise de correlação, conclui-se que o aumento no número de fibras musculares foi positivo sobre as características de crescimento e de carcaça dos suínos.

PALAVRAS-CHAVE: deposição de carne; diâmetro celular; gênero; grupos genéticos.

\section{MUSCLE FIBER, PERFORMANCE AND CARCASS QUALITY OF FOUR GENETIC GROUPS OF PIGS}

The objective of this study was to verify the performance and carcass quality of pigs from four genetic lines and to correlate these data with the number and diameter of muscle fibers. A total of48 pigs were used and distributed into four treatments: high-lean commercial crossbred line; prolificacy commercial crossbred line; (Landrace X Large White) crossbred animals; and undefined genetic line. The experimental design consisted of a complete randomized design with a 4 x 2 factorial arrangement (4 genetic lines and 2 genders). Daily weight gain, daily feed intake and the feed conversion were evaluated. At slaughtering, the carcasses were evaluated and the number and the diameter of the muscle fibers of longissimus dorsi were assessed. The high-lean commercial line presented the greatest number of muscle cells $(\mathrm{P}<0.05)$ while the Landrace $\mathrm{x}$ Large White crossbred line presented the greater diameter $(\mathrm{P}<0.05)$. High-lean commercial line showed a better performance and carcass characteristics compared with the undefined genetic line $(\mathrm{P}<0.05)$ and the barrows presented the lowest results $(\mathrm{P}<0.05)$. The increment in the muscle fiber number affected positively the performance and carcass characteristics of pigs.

KEYWORDS: diameter of the muscle fibers; genetic groups; lean deposition; gender. 


\section{INTRODUÇÃO}

Para atender a demanda e a exigência do atual mercado consumidor, a suinocultura tem dirigido esforços para a produção de animais com alto potencial de crescimento e deposição de carne magra. A melhoria no potencial de deposição de carne magra, velocidade de crescimento e eficiência alimentar do suíno em diferentes ambientes de criação e manejo, assegurando qualidade da carcaça no frigorífico, talvez sejam alguns dos objetivos mais desejados nos programas de melhoramento genético. Neste sentido, os ganhos genéticos conseguidos com os métodos modernos de identificação e seleção dos indivíduos com características superiores à média dos plantéis comerciais têm sido bastante significativos.

Segundo DWYER et al. (1993), o número de fibras musculares está relacionado com um crescimento mais rápido e eficiente do animal e tem efeito negativo na deposição de gordura (SEIDMAN et al., 1989). Vários pesquisadores verificaram que animais de linhagem de crescimento rápido têm mais fibras musculares que animais de linhagem de crescimento lento (EZEKWE \& MARTIN, 1975; DWYER et al., 1993; STICKLAND, 1996).

LEFAUCHEUR (2006) também sugere que o diâmetro celular é um parâmetro que pode estar relacionado com o rendimento de carne, quando não há diferença no número de fibras musculares, não obstante essa influência ainda gere muita discussão.

Neste sentido, objetivou-se com este trabalho verificar o desempenho e a qualidade da carcaça de quatro linhagens genéticas de suínos e correlacionar estes dados com o número e diâmetro das fibras musculares.

\section{MATERIAL E MÉTODOS}

O experimento foi conduzido no setor de suinocultura da Fazenda Escola e no Laboratório de Ciência da Carne, ambos pertencentes à Universidade Estadual de Londrina.

Foram utilizados 48 suínos, sendo 24 machos castrados e 24 fêmeas, 12 de cada linhagem genética, distribuídos em um delineamento experimental inteiramente casualizado em arranjo fatorial $4 \times 2$ (4 linhagens genéticas e 2 gêneros). As linhagens genéticas avaliadas foram: linhagem comercial melhorada para crescimento/produção de carne magra; linhagem comercial melhorada para fins de prolificidade; suínos resultantes de cruzamentos entre as raças Large White X Landrace; suínos sem genética definida. Os suínos entraram no experimento com peso vivo médio e idade inicial de $12,18 \pm 0,86 \mathrm{~kg}$ e $43 \pm 0,00$ dias; $12,21 \pm 1,48$ $\mathrm{kg}$ e $53 \pm 0,04$ dias; $12,07 \pm 1,57 \mathrm{~kg}$ e $49 \pm 0,03$ dias e; $12,11 \pm 1,44 \mathrm{~kg}$ e 41,83 $\pm 5,06$ dias, respectivamente.

$\mathrm{Na}$ análise do desempenho, a unidade experimental foi formada por dois animais de mesmo gênero alojados em uma mesma baia. Na análise das características da carcaça e fibra muscular, cada animal definiu uma unidade experimental. $\mathrm{Na}$ análise do desempenho foi verificado o ganho diário de peso, o consumo diário de ração e a conversão alimentar. As características de carcaça avaliadas foram peso de carcaça quente e resfriada, rendimento de carcaça, comprimento de carcaça, profundidade e área do músculo longissimus dorsi e espessura de toucinho.

Os suínos foram alojados em baias de alvenaria (dois indivíduos do mesmo gênero por baia), com piso compacto, com $3 \mathrm{~m}^{2}$ de área, equipadas com um bebedouro tipo nipple e comedouro semi-automático, onde foram alimentados ad libitum até o abate. As dietas experimentais (Tabela 1) foram fornecidas à vontade, sendo isonutrientes e formuladas para atender as exigências mínimas orientadas por ROSTAGNO (2005), de acordo com as diferentes fases: inicial (12 a $20 \mathrm{~kg}$ de peso vivo), crescimento I (20 aos $50 \mathrm{~kg}$ de peso vivo), crescimento II (50 aos $80 \mathrm{~kg}$ de peso vivo) e terminação (80 aos 100 kg de peso vivo).

Os suínos foram pesados semanalmente e no início do período de jejum pré-abate, para avaliar o ganho em peso. A ração fornecida foi pesada e o desperdício e as sobras no comedouro foram descontadas do total administrado. Assim, calculou-se o ganho diário de peso, o consumo diário de ração e a conversão alimentar.

Ao atingirem o peso médio de 100,00 $\pm 3,45$ $\mathrm{kg}$, os animais foram abatidos em um frigorífico comercial distante $45 \mathrm{~km}$ da Fazenda Escola. A ração foi retirada 12 horas antes do embarque, permanecendo os animais sob dieta hídrica até o abate. O embarque dos suínos foi realizado às seis horas da manhã, sendo o tempo de transporte até o frigorífico de aproximadamente uma hora. 
Tabela 1. Composição percentual e calculada das dietas experimentais para suínos utilizadas nas fases inicial (12 a $20 \mathrm{~kg}$ de peso vivo), crescimento I (20 a $50 \mathrm{~kg}$ de peso vivo), crescimento II (50 a $80 \mathrm{~kg}$ de peso vivo) e terminação (80 a $100 \mathrm{~kg}$ de peso vivo)

\begin{tabular}{|c|c|c|c|c|}
\hline Ingredientes (\%) & Inicial & Crescimento I & Crescimento II & Terminação \\
\hline Milho grão & 63,000 & 65,815 & 71,230 & 73,818 \\
\hline Farelo Soja & 30,000 & 26,164 & 21,104 & 18,744 \\
\hline Óleo bruto de soja & - & 3,269 & 3,107 & 3,051 \\
\hline Núcleo vitamínico/mineral ${ }^{(1)}$ & 4,000 & 4,000 & 4,000 & 4,000 \\
\hline L-lisina & - & 0,363 & 0,246 & 0,124 \\
\hline Dl-metionina & - & 0,139 & 0,062 & 0,013 \\
\hline Sal & - & 0,250 & 0,250 & 0,250 \\
\hline Açúcar & 3,000 & - & - & - \\
\hline Total & 100,000 & 100,000 & 100,000 & 100,000 \\
\hline \multicolumn{5}{|c|}{ Valores calculados ${ }^{(2)}$} \\
\hline Proteína Bruta (\%) & 18,80 & 17,70 & 15,70 & 14,70 \\
\hline Energia metabolizável (kcal/kg) & 3162 & 3319 & 3317 & 3316 \\
\hline Fibra Bruta (\%) & 2,71 & 2,55 & 2,37 & 2,29 \\
\hline Extrato etéreo (\%) & 2,77 & 5,74 & 5,71 & 5,71 \\
\hline Cálcio (\%) & 0,90 & 0,84 & 0,83 & 0,83 \\
\hline Fósforo total (\%) & 0,65 & 0,30 & 0,53 & 0,47 \\
\hline Lisina (\%) & 0,98 & 1,16 & 0,95 & 0,79 \\
\hline Metionina (\%) & 0,30 & 0,28 & 0,26 & 0,25 \\
\hline Treonina total (\%) & 0,74 & 0,68 & 0,60 & 0,57 \\
\hline Metionina + cistina (\%) & 0,61 & 0,71 & 0,59 & 0,52 \\
\hline
\end{tabular}

O processo de abate consistiu de insensibilização via corrente elétrica, com um equipamento da marca Petrovina ${ }^{\circledR}$ IS 2000 com dois eletrodos, utilizando-se 350 volts e 1,3 ampéres. A descarga elétrica foi aplicada por aproximadamente três segundos. A sangria foi realizada através do corte da veia jugular, com os animais na posição vertical, suspensos pelo membro posterior.

Após o abate, escaldagem e evisceração, as carcaças foram divididas ao meio longitudinalmente, pesadas (peso de carcaça quente) e resfriadas à temperatura de $2 \pm 1^{\circ} \mathrm{C}$, por 24 horas, na câmera de resfriamento do frigorífico. Após esse período, as carcaças foram novamente pesadas (peso de carcaça resfriada). A partir do peso vivo, obtido ao início do período de jejum, e o peso de carcaça quente, estimou-se o rendimento de carcaça.

As carcaças foram avaliadas individualmente de acordo com as orientações da ABCS (1973), para obtenção dos dados de comprimento de carcaça, profundidade do músculo longissimus dorsi, espessura de toucinho e área de olho de lombo. A espessura de toucinho e a profundidade do músculo longissimus dorsi foram medidas na altura da última costela, a $6 \mathrm{~cm}$ da linha média do corte.

Para a contagem e mensuração do diâmetro celular do longissimus dorsi, uma amostra foi retirada da meia carcaça esquerda, na altura da última costela. As amostras foram armazenadas em solução de Bouin por 24 horas, sendo então lavadas e mantidas em álcool 70\%. Posteriormente, o material foi desidratado, emblocado em parafina e colorido pela Hematoxilina e Eosina para a preparação das lâminas.

O número médio de fibras musculares foi estimado indiretamente pela contagem aleatória de 13 campos (capturados ao acaso), com o auxílio de uma Câmera digital Pro-series 3-chipcolor e um microscópio Olympus BX 50. O número total de fibras do músculo (NTF) foi estimado pela fórmula:

$$
N T F=\frac{A T \times N F C}{C \times A C}
$$

Em que: $\mathrm{AT}=$ Área total do músculo; NFC = Número de fibras contadas em todos os campos; $\mathrm{C}=$ Número de campos lidos; AC = Área de cada campo lido. 
Para determinação do diâmetro da fibra muscular foram capturados 13 campos de cada lâmina e medido o menor diâmetro de 15 fibras por campo, totalizando 195 fibras por lâmina.

Os resultados foram submetidos à análise de variância utilizando-se o programa estatístico SAEG (1993) e as médias foram comparadas pelo teste de Duncan ao nível de 5\% de significância. Para a análise de correlação foi utilizando o teste de Pearson.

\section{RESULTADOS E DISCUSSÃO}

Os resultados referentes ao número e diâmetro das fibras do longissimus dorsi estão apresentados na Tabela 2. As linhagens comerciais apresentaram o maior número de fibras musculares no longissimus dorsi $(\mathrm{P}<0,05)$. Os animais sem genética definida apresentaram menor número de fibras comparado com os outros grupos.

Tabela 2: Médias do número e diâmetro de fibras no longissimus dorsi para diferentes linhagens e gêneros de suínos

\begin{tabular}{lcc}
\hline \multicolumn{1}{c}{ Linhagens } & Número de fibras $(\mathrm{x} 1000)$ & Diâmetro $\left(\mu \mathrm{m}^{2}\right)$ \\
\hline Linhagem (carne) & $1.032,436 \pm 88,78 \mathrm{a}$ & $40,58 \pm 3,66 \mathrm{ab}$ \\
Linhagem (prolificidade) & $1.021,267 \pm 189,08 \mathrm{a}$ & $37,43 \pm 2,50 \mathrm{~b}$ \\
Landrace X Large White & $998,366 \pm 153,02 \mathrm{a}$ & $44,00 \pm 7,01 \mathrm{a}$ \\
Sem genética definida & $870,552 \pm 76,99 \mathrm{~b}$ & $39,54 \pm 5,60 \mathrm{~b}$ \\
\hline \multicolumn{1}{c}{ Gênero } & & $39,78 \pm 6,21$ \\
\hline Macho castrado & $960,211 \pm 156,85$ & $41,01 \pm 4,44$ \\
Fêmea & $1.004,072 \pm 135,91$ & 40,30 \\
\hline Média geral & 979.144 & 12,15 \\
\hline CV (\%) & 13,98 &
\end{tabular}

Médias seguidas de letras distintas diferem entre si pelo teste de Duncan $(\mathrm{P}<0,05)$.

Entre os gêneros não foi observada diferença $(\mathrm{P}>0,05)$ para o número de fibras no músculo longissimus dorsi, concordando com MILLER et al. (1975).

Os animais cruzados Large White $\mathrm{x}$ Landrace e a linhagem selecionada para deposição de carne apresentaram maior diâmetro celular no longissimus dorsi $(\mathrm{P}<0,05)$ e os animais sem genética definida e a linhagem melhorada para prolificidade apresentaram o menor diâmetro $(\mathrm{P}<0,05)$; entretanto, as linhagens selecionadas para deposição de carne não diferiram do segundo grupo. Esses resultados concordam parcialmente com STICKLAND (1996) e LARZUL et al. (1997), que observaram que animais com um maior número de fibras musculares apresentam fibras de menor diâmetro. Segundo MILLER et al. (1975), suínos selecionados para o crescimento rápido apresentam maior número de fibras, porém de menor diâmetro. O aumento do número de fibras musculares em suínos está associado ao rápido crescimento e à maior proporção de tecido magro.

Os valores médios observados para as características de desempenho estão apresentados na Tabela 3. Para o ganho diário em peso foi observada diferença $(P<0,05)$ entre os grupos genéticos. Suínos da linhagem prolificidade apresentaram melhor ganho diário em peso, seguidos dos grupos genéticos da linhagem carne e cruzamento Landrace x Large White. Os suínos sem genética definida apresentaram o menor ganho diário em peso. Observa-se que a linhagem sem genética definida foi a que apresentou o menor número de fibras musculares e o menor ganho em peso, confirmando a associação positiva entre o número de fibras e a velocidade de crescimento dos suínos.

Para ganho diário em peso houve interação entre grupos genéticos e os gêneros (Tabela 4). Os machos e as fêmeas da linhagem genética melhorada para prolificidade apresentaram ganho diário em peso maior que os machos e as fêmeas dos demais grupos $(\mathrm{P}<0,05)$. As fêmeas do grupo de animais não melhorados tiveram as menores médias para a característica ganho diário de peso $(\mathrm{P}<0,05)$, enquanto que as fêmeas melhoradas para deposição de carne não diferiram das fêmeas híbridas selecionadas para prolificidade e das fêmeas provenientes do cruzamento Landrace $\mathrm{x}$ Large White $(\mathrm{P}>0,05)$. Os machos castrados sem genética definida apresentaram ganho diário de peso maior que as fêmeas $(\mathrm{P}<0,05)$; entretanto, essa diferença não foi observada nos demais grupos. 
Tabela 3. Médias das características do ganho diário em peso (GDP), consumo diário de ração (CDR), conversão alimentar (CA), idade aos $100 \mathrm{~kg}$ de peso vivo (idade aos $100 \mathrm{~kg}$ ) para suínos das diferentes linhagens e gêneros

\begin{tabular}{lcccc}
\hline Linhagens & $\begin{array}{c}\text { GDP } \\
(\mathrm{kg} / \mathrm{dia})\end{array}$ & $\begin{array}{c}\text { CDR } \\
(\mathrm{kg} / \mathrm{dia})\end{array}$ & CA & $\begin{array}{c}\text { Idade aos 100 kg } \\
\text { (dias) }\end{array}$ \\
\hline Linhagem (carne) & $0,876 \pm 0,02 \mathrm{~b}$ & $1,980 \pm 0,19 \mathrm{a}$ & $2,255 \pm 0,22 \mathrm{a}$ & $140,950 \pm 7,02 \mathrm{a}$ \\
Linhagem (prolificidade) & $0,928 \pm 0,08 \mathrm{a}$ & $2,230 \pm 0,16 \mathrm{~b}$ & $2,410 \pm 0,17 \mathrm{a}$ & $143,850 \pm 7,59 \mathrm{a}$ \\
Landrace x Large White & $0,872 \pm 0,03 \mathrm{~b}$ & $2,100 \pm 0,32 \mathrm{ab}$ & $2,396 \pm 0,29 \mathrm{a}$ & $141,600 \pm 7,32 \mathrm{a}$ \\
Sem genética definida & $0,830 \pm 0,08 \mathrm{c}$ & $2,180 \pm 0,30 \mathrm{~b}$ & $2,626 \pm 0,29 \mathrm{~b}$ & $154,710 \pm 11,42 \mathrm{~b}$ \\
\hline Gênero & & & \\
\hline Macho castrado & $0,898 \pm 0,05 \mathrm{a}$ & $2,243 \pm 0,28 \mathrm{~b}$ & $2,499 \pm 0,28 \mathrm{~b}$ & $142,080 \pm 7,82 \mathrm{a}$ \\
Fêmea & $0,856 \pm 0,07 \mathrm{~b}$ & $2,010 \pm 0,18 \mathrm{a}$ & $2,353 \pm 0,25 \mathrm{a}$ & $148,830 \pm 11,02 \mathrm{~b}$ \\
\hline Média geral & 0,877 & 2,120 & 2,430 & 145,450 \\
\hline CV (\%) & 3,896 & 10,030 & 9,848 & 5,200 \\
\hline
\end{tabular}

Médias seguidas de letras distintas diferem entre si pelo teste de Duncan $(\mathrm{P}<0,05)$.

Para o consumo diário de ração, os animais melhorados para característica de crescimento apresentaram menor consumo $(\mathrm{P}<0,05)$ em relação ao grupo de animais sem genética definida, mas não diferiram do grupo proveniente de animais cruzados Large White x Landrace. Para o gênero, os machos castrados apresentaram maior consumo $(\mathrm{P}<0,05)$, porém não houve interação entre os grupos genéticos e o gênero. As diferenças observadas entre os gêneros foram semelhantes aos resultados obtidos por CISNEROS et al. (1996) e HAMILTON et al. (2003), que verificaram que os machos castrados consumiram mais ração que as fêmeas.

Tabela 4. Interação entre linhagem e gênero para a variável ganho diário de peso (GDP)

\begin{tabular}{lcccc}
\hline \multirow{2}{*}{ Gênero } & \multicolumn{4}{c}{ Linhagens } \\
\cline { 2 - 5 } & $\begin{array}{c}\text { Linhagem } \\
\text { (carne) }\end{array}$ & $\begin{array}{c}\text { Linhagem } \\
\text { (prolificidade) }\end{array}$ & $\begin{array}{c}\text { Landrace X Large } \\
\text { White }\end{array}$ & $\begin{array}{c}\text { Sem genética } \\
\text { definida }\end{array}$ \\
\hline $\begin{array}{l}\text { Macho } \\
\text { castrado }\end{array}$ & $0,866 \pm 0,02 \mathrm{aB}$ & $0,947 \pm 0,05 \mathrm{aA}$ & $0,891 \pm 0,02 \mathrm{aB}$ & $0,882 \pm 0,04 \mathrm{aB}$ \\
Fêmea & $0,886 \pm 0,02 \mathrm{aAB}$ & $0,909 \pm 0,04 \mathrm{aA}$ & $0,851 \pm 0,02 \mathrm{aB}$ & $0,779 \pm 0,04 \mathrm{bC}$ \\
\hline
\end{tabular}

Médias seguidas de letras maiúsculas distintas, nas linhas, e de letras minúsculas, nas colunas, diferem entre si no teste de Duncan $(\mathrm{P}<0,05)$.

Quanto à conversão alimentar, o grupo de animais não melhorados comercialmente apresentou o pior índice $(\mathrm{P}<0,05)$ em relação aos demais. Os machos foram piores que as fêmeas $(\mathrm{P}<0,05)$ para a característica, não havendo interação entre os gêneros e os grupos genéticos.

Em relação à idade ao abate, os animais de linhagens não melhoradas atingiram o peso de 100 $\mathrm{kg}$ mais tardiamente $(\mathrm{P}<0,05)$ que as demais linhagens (aproximadamente 14 dias de diferença daqueles de linhagem comerciais selecionados para deposição de carne). Se comparados somente dentro do período experimental, observa-se que os suínos não melhorados demoraram, em média, 20 dias a mais para atingir o peso de abate. BULLOCK et al. (1991) verificaram que suínos provenientes do cruzamento entre Duroc e Landrace apresentaram idade de abate mais precoce (15,9 dias a menos) que leitões oriundos de linhagem não selecionada. Esses resultados indicam que animais com mais fibras musculares são mais precoces ao peso ao abate. Os machos castrados atingiram o peso ao abate aproximadamente 7 dias mais cedo que as fêmeas $(\mathrm{P}<0,05)$.

O grupo de suínos sem genética definida foram os que apresentaram menor número de células musculares e pior conversão alimentar. Esses resultados estão de acordo com DWYER et al. (1993). BARK et al. (1992) observaram que suínos de alto potencial para deposição de carne magra apresentaram melhor conversão alimentar que suínos de baixo potencial para deposição de carne magra, 
crescendo mais rápido e consumindo menos ração por unidade de ganho em peso.

Na Tabela 5 estão apresentados os resultados referentes às características de carcaça. Não houve diferença $(\mathrm{P}>0,05)$ entre as linhagens para as características peso de carcaça quente e peso de carcaça fria. Os maiores rendimentos de carcaça foram obtidos, respectivamente, pelos animais selecionados para deposição de carne, não melhorados geneticamente e cruzados Landrace $\mathrm{x}$ Large White, enquanto que os da linhagem prolificidade apresentaram os piores rendimentos de carcaça $(\mathrm{P}<0,05)$. Os machos, todavia, apresentaram rendimentos inferiores às fêmeas $(\mathrm{P}<0,05)$.

Quanto ao comprimento de carcaça, os animais provenientes do cruzamento Landrace $\mathrm{x}$ Large White apresentaram carcaças mais compridas que os das linhagens comerciais selecionados para carne e para prolificidade $(\mathrm{P}<0,05)$. As linhagens selecionadas para prolificidade não diferiram das demais linhagens $(\mathrm{P}>0,05)$ e os machos castrados tiveram menor comprimento de carcaça que as fêmeas $(\mathrm{P}<0,05)$. Resultados de pesquisas indicam que animais de linhagem magra tendem a ter carcaças mais compridas e mais pesadas que suínos de linhagem obesa (SEIDMAN et al., 1989; WISEMAN, 2006).
Para a profundidade do músculo longissimus dorsi, as linhagens comerciais apresentaram maiores médias $(\mathrm{P}<0,05)$ comparados com os animais sem genética definida, que têm menos fibras musculares. Os animais provenientes do cruzamento Landrace $\mathrm{x}$ Large White não diferiram das demais linhagens $(\mathrm{P}>0,05)$ e os machos castrados apresentaram menor profundidade de músculo que as fêmeas $(\mathrm{P}<0,05)$. MILLER et al. (1975) verificaram que o aumento no número de fibras no músculo longissimus dorsi estava associado a maior proporção de tecido magro na carcaça.

Para a espessura de toucinho os grupos de suínos selecionados para carne e os para prolificidade apresentaram valores menores $(\mathrm{P}<0,05)$ em relação aos demais grupos, indicando menor deposição deste tecido. Os machos castrados apresentaram maior espessura de toucinho, havendo interação entre os grupos genéticos e os gêneros, sendo que somente os machos castrados do grupo de animais não melhorados e do cruzamento Landrace $\mathrm{x}$ Large White apresentaram maior espessura de toucinho que as fêmeas do mesmo grupo. A profundidade de músculo se relaciona negativamente com a deposição de gordura na carcaça e sinergicamente com a área de olho de lombo, sendo que animais com menor espessura de toucinho comumente têm maior profundidade de músculo.

Tabela 5. Peso de carcaça quente (PCQ), peso de carcaça fria (PCF), rendimento de carcaça (RC), comprimento de carcaça (CC), profundidade de músculo (PM), espessura de toucinho (ET) e área de olho de lombo (AOL) de suínos de diferentes linhagens e gêneros

\begin{tabular}{lccccccc}
\hline Linhagens & PCQ $(\mathrm{kg})$ & PCF $(\mathrm{kg})$ & RC & CC $(\mathrm{cm})$ & PM $(\mathrm{mm})$ & ET & AOL $\left(\mathrm{cm}^{2}\right)$ \\
\hline $\begin{array}{l}\text { Linhagem } \\
\text { Carne }\end{array}$ & $76,60 \pm 1,41$ & $72,00 \pm 1,34$ & $76,80 \pm 1,39 \mathrm{a}$ & $91,82 \pm 3,13 \mathrm{~b}$ & $61,72 \pm 3,44$ a & $13,31 \pm 1,77 \mathrm{c}$ & $37,85 \pm 2,71 \mathrm{a}$ \\
$\begin{array}{l}\text { Linhagem } \\
\text { prolificidade }\end{array}$ & $76,90 \pm 3,80$ & $75,16 \pm 3,74$ & $75,35 \pm 1,89 \mathrm{~b}$ & $94,42 \pm 3,48 \mathrm{ab}$ & $61,62 \pm 5,89 \mathrm{a}$ & $15,91 \pm 3,41 \mathrm{c}$ & $36,77 \pm 4,53 \mathrm{a}$ \\
$\begin{array}{l}\text { Landrace x } \\
\text { Large White }\end{array}$ & $75,93 \pm 2,04$ & $74,17 \pm 2,02$ & $75,70 \pm 1,35 \mathrm{ab}$ & $97,09 \pm 3,08 \mathrm{a}$ & $56,83 \pm 8,82 \mathrm{ab}$ & $20,89 \pm 7,75 \mathrm{~b}$ & $35,48 \pm 3,57 \mathrm{a}$ \\
$\begin{array}{l}\text { Sem genética } \\
\text { definida }\end{array}$ & $77,61 \pm 2,75$ & $75,82 \pm 2,69$ & $76,72 \pm 1,24 \mathrm{a}$ & $91,83 \pm 4,39 \mathrm{~b}$ & $53,51 \pm 8,91 \mathrm{~b}$ & $28,28 \pm 6,92 \mathrm{a}$ & $32,64 \pm 7,06 \mathrm{~b}$ \\
\hline
\end{tabular}

Gênero

\begin{tabular}{lccccccc}
\hline Macho castrado & $76,32 \pm 3,14$ & $73,28 \pm 3,10$ & $75,56 \pm 1,57 \mathrm{~b}$ & $92,65 \pm 4,48 \mathrm{~b}$ & $55,53 \pm 8,44 \mathrm{~b}$ & $22,15 \pm 9,26$ a & $32,77 \pm 4,46 \mathrm{~b}$ \\
Fêmea & $77,24 \pm 2,06$ & $75,41 \pm 2,03$ & $76,72 \pm 1,40 \mathrm{a}$ & $94,87 \pm 3,39 \mathrm{a}$ & $61,23 \pm 5,91 \mathrm{a}$ & $17,26 \pm 5,41 \mathrm{~b}$ & $38,51 \pm 3,68 \mathrm{a}$ \\
\hline Média geral & 76,78 & 74,34 & 76,14 & 93,76 & 58,38 & 19,71 & 35,65 \\
\hline CV (\%) & 3,55 & 7,03 & 1,82 & 3,62 & 11,21 & 23,26 & 9,38 \\
\hline
\end{tabular}

Médias seguidas de letras distintas diferem entre si pelo teste de Duncan $(\mathrm{P}<0,05)$.

Na Tabela 6 estão apresentados os resultados da correlação entre as características histológicas do longissimus dorsi e as características de desempenho. A correlação fenotípica entre o número e o diâmetro celular foi negativa e moderada $(-0,33)$, indicando que quanto mais fibras musculares, menor tende a ser seu diâmetro. A correlação fenotípica entre o número de fibras e a conversão alimentar e a idade aos $100 \mathrm{~kg}$ de peso vivo foi de moderada a baixa, indicando que animais com mais fibras musculares têm melhor conversão alimentar e atingem os $100 \mathrm{~kg}$ de peso vivo mais precocemente. 
Tabela 6. Correlações entre número de fibras e diâmetro celular do músculo longissimus dorsi e características de desempenho e de carcaça

\begin{tabular}{lcc}
\hline Parâmetros & Número de fibras & Diâmetro celular \\
\hline Número de fibras & 1,00 & $-0,33^{*}$ \\
Diâmetro celular & - & 1,00 \\
Consumo diário de ração & $-0,14$ & $-0,29^{*}$ \\
Ganho diário de peso & 0,21 & $-0,25^{*}$ \\
Conversão alimentar & $-0,26^{*}$ & $-0,17$ \\
Idade aos 100 kg & $-0,24^{*}$ & 0,15 \\
Profundidade do músculo & $0,40^{*}$ & 0,08 \\
Espessura de toucinho & $-0,56^{*}$ & 0,07 \\
Área de olho de lombo & $0,59^{*}$ & 0,01 \\
Comprimento de carcaça & 0,48 & 0,09 \\
Rendimento de carcaça & $-0,01$ & 0,11 \\
Porcentagem de carne na carcaça & $0,54^{*}$ & $-0,11$ \\
Quantidade de carne na carcaça & $0,55^{*}$ & $-0,06$ \\
\hline
\end{tabular}

* Correlação estatisticamente significativa ao nível de 5\%.

A correlação entre o número de fibras e as características de carcaça apresentou valores de moderado a alto, sendo negativo para a espessura de toucinho e positivo para as características de profundidade de músculo, área de olho de lombo, porcentagem de carne magra e quantidade de carne magra na carcaça. Os resultados apontam que animais com mais fibras musculares produzem carcaças com menor espessura de toucinho, maior profundidade de músculo e área de olho de lombo. Esses animais ainda têm maior porcentagem de carne e maior quantidade de carne magra na carcaça.

A correlação entre o diâmetro das fibras musculares e o consumo diário de ração e o ganho diário de peso foi negativa e de moderada a baixa indicando que animais que têm fibras musculares de maior diâmetro consomem menos ração por dia e têm menor crescimento diário que animais que exibem fibras musculares de menor diâmetro.

\section{CONCLUSÕES}

O incremento no número de fibras musculares de suínos atua de maneira positiva nas características de crescimento e de qualidade da carcaça, produzindo animais precoces ao peso de abate e com maior deposição de carne magra na carcaça.

Há grande influência do gênero sobre as características de desempenho e qualidade de carcaça. Os machos castrados crescem mais rapidamente, porém apresentam maior deposição de gordura na carcaça que as fêmeas.

\section{REFERÊNCIAS}

ASSOCIAÇÃO BRASILEIRA DE CRIADORES DE SUÍNOS - ABCS. Método brasileiro de classificação de carcaças. 2ed. Rio Grande do Sul, 1973.

BARK, L.J.; STAHLY, T.S.; CROMWELL, G.L.; MIYAT, J. Influence of genetic capacity for lean tissue growth on rate and efficiency of tissue accretion in pigs fed ractopamine. Journal of Animal Science, v. 70, n.11, p.3391-3400, 1992.

BULLOCK, K.D.; KUHLERS, D.L. e JUNGST, S.B. Effects of mass selection for increased weight at two ages on growth rate and carcass composition of duroc-landrace pigs. Journal of Animal Science, v.69, n.4, p.1409-1419, 1991.

CISNEROS, F.; ELLIS, M.; McKEITH, F.K.; McCAW, J.; FERNANDO, R.L. Influence of slaughter weight on growth and carcass charatcteristics, commercial cutting and curing yields, and meat quality of barrows and gilts from two genotypes. Journal of Animal Science, v.74, n.5, p. 925-933, 1996.

DWYER, C.M.; FLETCHER, J.M. e STICKLAND, N.C. Muscle cellularity and postnatal growth in the pig. Journal of Animal Science, v. 71, V. 12, p. 3339, 1993.

EZEKWE, M.O. e MARTIN, R.J. Cellular characteristics of skeletal muscle in selected strains of pigs and mice and the unselected controls. Growth, v. 39, n.1, p. 95-106, 1975

HAMILTON, D.N.; ELLIS, M.; WOLTER, B.F.; SHINCKEL, A.P; WILSON, E.R. The growth performance of the progeny of two swine sire lines reared under different floor space allowances. Journal of Animal Science, v.81, n.5, p.1126-1135, 2003.

HANDEL, S.E.; STICKLAND, N.C. - Catch-Up Growth In Pigs: A Relationship With Muscle Cellularity. Animal Production, v.47, n.2, p.291-295, 1988. 
HOSHI, E. H.; FONSECA, N.A.N.; PINHEIRO, J.W. BRIDI, A.M; SILVA, C.A. Muscle fiber number and growth performance of pigs from sows treated with ractopamine. Asian-Australasian Journal of Animal Science, v. 18, n.10, p.1492-1497, 2005

LARZUL, C.; LEFAUCHEUR, L. ; ECOLAN, P.; GOGUE, A.; SELLIER,P.; LEROY, P. MONIN,G. Phenotypic and genetic parameter for longissimus muscle fiber characteristics in relation to growth, carcass, and meat quality traits in large white pigs. Journal of Animal Science, v. 75, n.12, p. 3126-3137, 1997.

LEFAUCHEUR, L. Myofibre typing and its relationships to growth performance and meat quality. Archiv fur Tierzucht, 49, Special Issue, p. 04-17, 2006.

MILLER, L.R.; GARWOOD, V.A.; JUDGE, M.D. Factors affecting porcine muscle fiber type, diameter and number. Journal of Animal Science, v. 41, p. 66-77, 1975.

NRC. Nutrient requirements of swine. 10th ed. National Academy Press, Washington, DC, 1998.

ROSTAGNO, H.S. (editor) Tabelas brasileiras para aves e suínos: composição de alimentos e exigências nutricionais. Viçosa: UFV, 2005. 186 p.
SAEG. Sistema para análises estatísticas; versão 5.0. Viçosa, MG: Fundação Arthur Bernardes, 1993.

SEIDMAN, S.C.; CROUSE, J.D. e MERSMANN, H.J. Carcass, muscle and meat characteristics of lean and obese pigs. Journal of Animal Science, v. 67, n. 11, p. 29502955, 1989.

SOBESTIANSKY, J.; WENTZ, I.; SILVEIRA, P.R.S.; SESTI, L.A. Suinocultura intensiva, produção, manejo e saúde do rebanho. Embrapa; Serviço de Produção de Informação, SPI; Brasília, 1998.

STICKLAND, N.C. Pre-natal influence on post-natal growth. The Royal Veterinary College, v.11, n.8, p.21, 1996.

WISEMAN, T. G. Genetic and gender influences on the changing phenotypic, total body and body component mineral compositions of pigs from 20 to 125 kilogram body weight. Dissertation presented in partial fulfillment of the requirement for the degree doctor of Philosophy in the Graduate School of The Ohio State University, The Ohio State University, 2006. Disponível em http://etd.ohiolink.edu/send-

pdf.cgi/Wiseman\%20Theodore\%20G.pdf?osu1141655387 , acesso em junho de 2009. 